\title{
AN IMPROVED SILVER STAINING PROCEDURE FOR SCHIZODEME ANALYSIS IN POLYACRYLAMIDE GRADIENT GELS
}

\author{
ANTONIO M. GONÇALVES; NEDIA S. NEHME \& CARLOS M. MOREL
}

Instituto Oswaldo Cruz, Departamento de Bioquímica e Biologia Molecular, Caixa Postal 926, 20001

Rio de Janeiro, RJ, Brasil

\begin{abstract}
A simple protocol is described for the silver staining of polyacrylamide gradient gels used for the separation of restriction fragments of kinetoplast DNA [schizodeme analysis of trypanosomatids (Morel et al., 1980)]. The method overcomes the problems of non-uniform staining and strong background color which are frequently encountered when conventional protocols for silver staining of linear gels are applied to gradient gels. The method described has proven to be of general applicability for DNA, RNA and protein separations in gradient gels.
\end{abstract}

Key words: silver staining - schizodeme analysis - DNA - RNA - protein - trypanosomatids

Schizodeme analysis $($ schizo $=$ cleave, demos $=$ population), a technique for the genotypic characterization of trypanosomatids, was introduced by Morel et al. (1980) and modified by Gonçalves et al. (1984). It is based on the electrophoretic separation of restriction-endonuclease generated fragments of kinetoplast DNA (kDNA), the abundant and unique mitochondrial DNA that defines the order Kinetoplastida.

In this paper we describe a methodology for silver staining of DNA fragments in polyacrylamide gradient gels and its application in schizodeme analysis.

\section{MATERIALS AND METHODS}

Schizodeme analysis - The technique is based on the protocols described by Morel et al. (1980) and Gonçalves et al. (1984). Parasites are lysed using a strong detergent (sarkosyl) and digested with pronase at $60^{\circ} \mathrm{C}$. The kDNA networks are collected by centrifugation, extracted with phenol-chloroform and precipitated with ethanol.

The kDNA obtained is digested with restriction enzymes and uncubated with proteinase

This research was supported by grants from the UNDP/World Bank/WHO Special Programme for Research and Training in Tropical Diseases (Geneva), CNPq and FINEP (Brazil).

Received November 10, 1989.

Accepted January 17, 1990.
K. The electrophoretic analysis of the restriction fragments is carried out overnight at room temperature in a high resolution $5.10 \%$ linear polyacrylamide gradient gel, $130 \times 135 \times 1 \mathrm{~mm}$ (W $\times \mathrm{H} \times \mathrm{T})$ in a vertical apparatus, using $1 \mathrm{X}$ TBE as buffer and a constant current of $8 \mathrm{~mA}$.

Protocol for silver staining - The following steps were followed:

Step 1: after the electrophoretic run, wash the gel with $250 \mathrm{ml}$ of $1 \mathrm{X}$ wash buffer for 30 min (1X wash buffer is $78.4 \mathrm{mM}$ phosphate, $21.6 \mathrm{mM}$ citrate, $\mathrm{pH} 3.0$ ). Stock $10 \mathrm{X}$ wash buffer is made by mixing $200 \mathrm{ml} 1 \mathrm{M}$ sodium phosphate monobasic with $55 \mathrm{ml} 1 \mathrm{M}$ citric acid.

Step 2: fix the gel (unstained or stained with ethidium bromide) with $200 \mathrm{ml}$ of $50 \%$ methanol $-10 \%$ trichloroacetic acid for $30 \mathrm{~min}$.

Step 3: wash two times with $250 \mathrm{ml}$ of $5 \%$ acetic acid $-10 \%$ ethanol for $20 \mathrm{~min}$.

Step 4: wash two times with $250 \mathrm{ml}$ for $10 \%$ ethanol for $10 \mathrm{~min}$.

Step 5: soak the gel in $200 \mathrm{ml}$ of silver staining solution. This solution is made by mixing $40 \mathrm{ml}$ of $0.1 \mathrm{M}$ sodium hydroxide, 3 $\mathrm{ml}$ of concentrated ammonium hydroxide and $1 \mathrm{~g}$ of silver nitrate dissolved in $10 \mathrm{ml}$ of water. Mix until the black precipitate is dissolved and adjust final volume to $200 \mathrm{ml}$ with water. Stain the gel in this solution for 40 min. 
Step 6: wash with $300 \mathrm{ml}$ of water for 5 $\min$.

Step 7: develop the gel with $300 \mathrm{ml}$ of fresh solution of $0.01 \%(30 \mathrm{mg})$ citric acid, containing $450 \mu \mathrm{l}$ of $35 \%$ formaldehyde. When development is complete, the DNA bands will appear dark brown or black against a yellowish background.

Step 8: stop development by soaking the gel in $20 \%$ ethanol $-5 \%$ acetic acid. Leave the gel in this solution until the background turns light yellow in colour.

Step 9: wash the gel three times (first wash for $30 \mathrm{~min}$ and the other two for $60 \mathrm{~min}$ ) with $250 \mathrm{ml}$ of $20 \%$ ethanol. If necessary the gel can be kept in this solution for several days without damage at room temperature.

Note: all the above steps are carried out with mild agitation. Wear rubber or polyvinil gloves to hold the gel in order to avoid the appearance of spots. The quality of the water used seems to be critical for the silver staining protocol. Use double distilled or deionized water.

Drying the gel - Soak the gel in $200 \mathrm{ml}$ of $20 \%$ ethanol $-1 \%$ glycerol for three hours, with mild agitation, at room temperature. Dry between two sheets of permeable cellophane paper.

With apparatus: we use a slab gel dryer under vacuum, without mylar sheet on the gel, at $80^{\circ} \mathrm{C}$ for $60 \mathrm{~min}$.

Without apparatus: wrap a glass plate with a plastic film (Saranwrap). Place on the plate a sheet of wet cellophane paper longer than the plate and remove all air bubbles. Place the gel on the covered plate and place another sheet of cellophane paper, treated as above on top. Remove air bubbles, fold the cellophane paper behind the plate and finally cover with another glass plate of the same size. Hold the whole system with the aid of bulldog clips. With a needle, pierce the cellophane paper all around the gel to remove air bubbles and excess water. This assembled gel should be stored at $37^{\circ} \mathrm{C}$ for twelve hours.

Note: after drying, the gel can be plasticized or simply kept protected against humidity.
Contact prints can be made using the dried gel as a photographic negative.

Destaining the gel - If the gel becomes overstained, it can be destained as follows: after stoping development wash the gel in distilled water with agitation for $10 \mathrm{~min}$. Soak the gel in $100 \mathrm{ml}$ of a solution containing $0.012 \%$ potassium permanganate (prepare $0.4 \%$ stock solution and use $3 \mathrm{ml}$ ) and $1 \%$ glacial acetic acid, keeping it under agitation. When the gel reaches the desired colour, stop the reaction by soaking it in a $4 \%$ sodium, sulphite solution. Wash the gel for $30 \mathrm{~min}$ (three times) in water and afterwards in $20 \%$ ethanol.

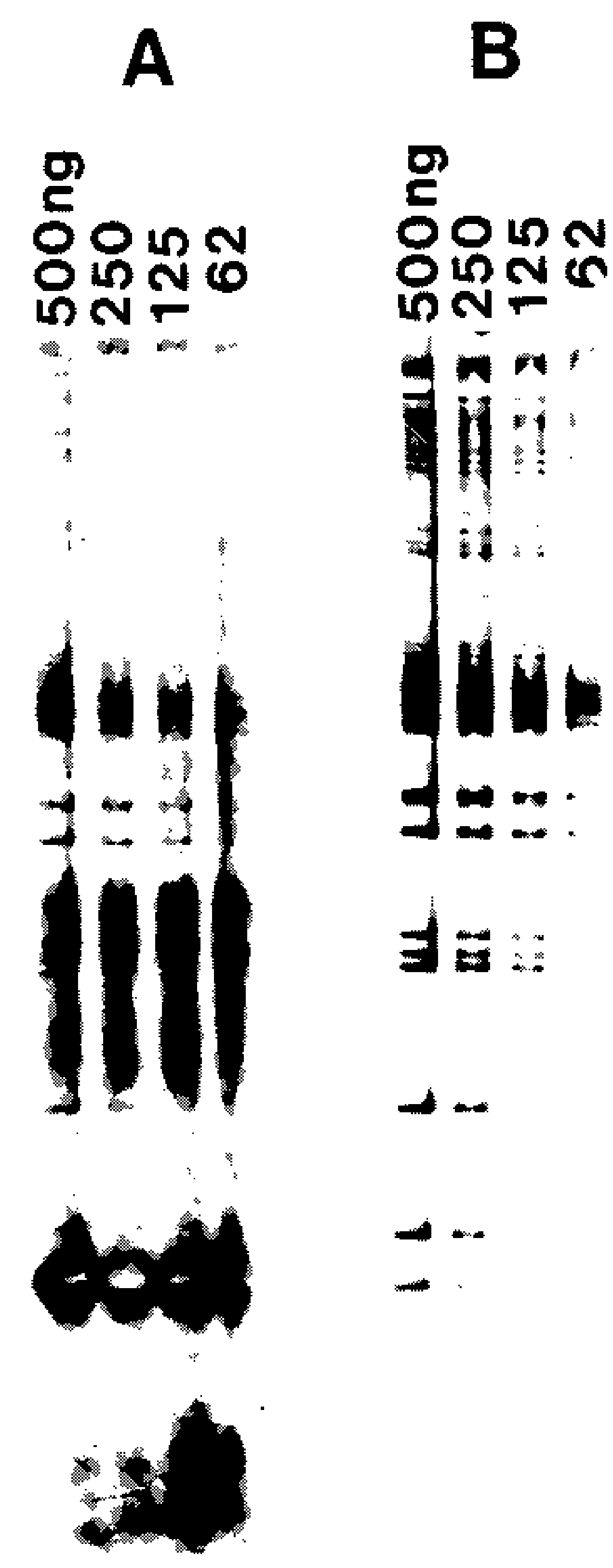

Fig. 1: 5-10\% polyacrylamide gradient gel stained with silver, as described in the text, containing kDNA of Trypanosoma cruzi digested with EcoRI. A) Without treatment with proteinase K. B) Treated with proteinase $\mathrm{K}(2 \mu \mathrm{g} / \mathrm{kg} \mathrm{kDNA} / 1-2 \mathrm{u}$ restriction enzyme) 

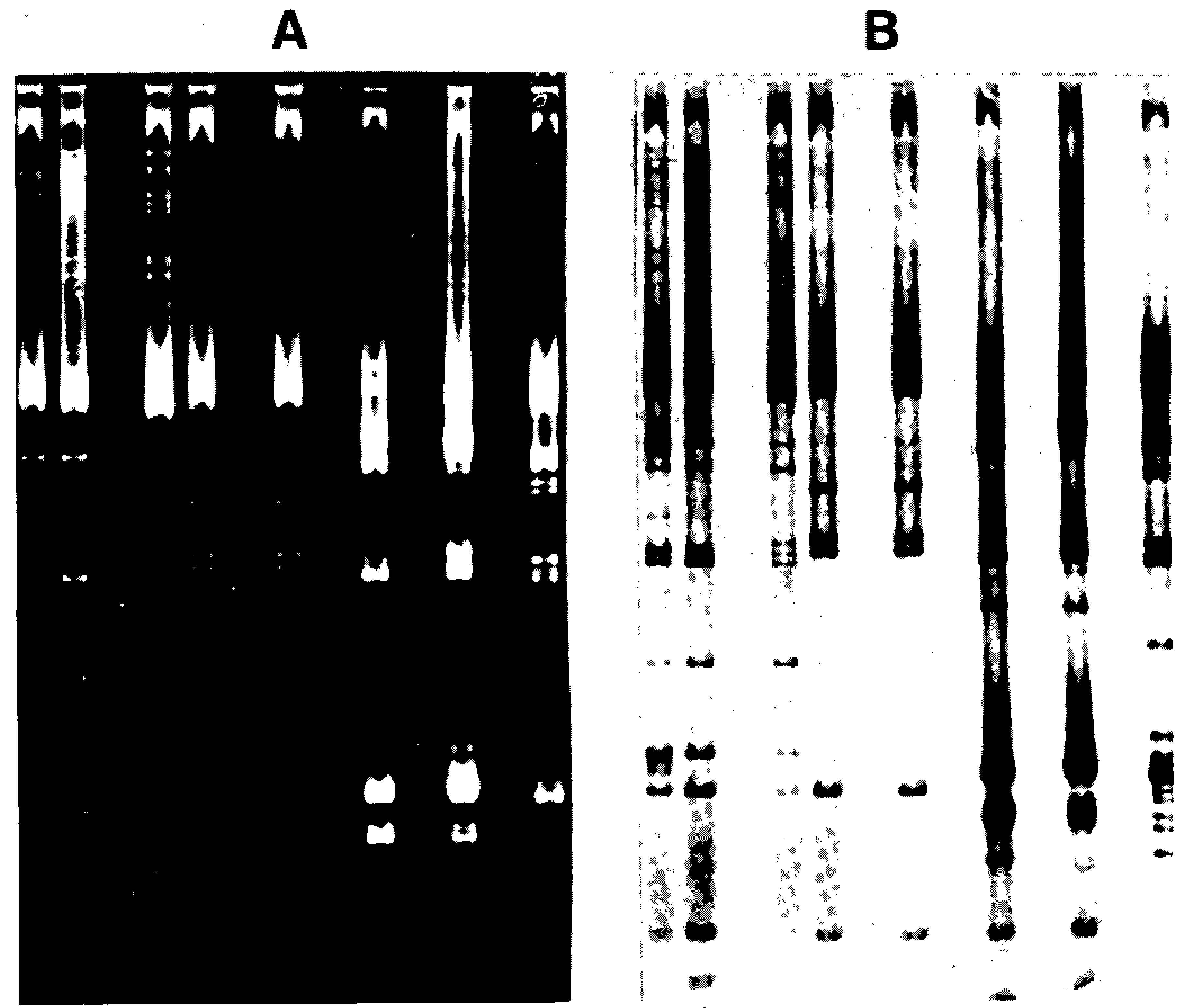

Fig. 2: $5-10 \%$ polyacrylamide gradient gel containing kDNA of different strains of Trypanosoma cruzi digested with EcoRI. A) Stained with ethidium bromide. B) Stained with silver, as described in the text.

\section{RESULTS AND DISCUSSION}

Several methods have been described for silver staining in regular polyacrylamide gels of proteins (Oakley et al., 1980; Merril et al., 1981; Schleider \& Watterson, 1983) or nucleic acids (Boulikas \& Hancock, 1981; Herring et al., 1982; Beidler et al., 1982; Guillemette \& Lewis, 1983). Some of these authors have already shown that silver staining is more sensitive than Coomassie blue for the detection of proteins or ethidum bromide for nucleic acids.

When these techniques are applied to gradient gels (which are required for schizodeme analysis), the staining obtained is not uniform. A strong, dark-yellow background colour is allways present in the regions of high acrylamide concentration making difficult the viasualization and analysis of the bands of lower molecular weight. The technique we describe here over- comes these problems and has the additional advantage that the same protocol can be used without modifications for protein and/or nucleic acid staining.

For the silver staining of nucleic acids it is important that the material be free of proteins. Fig. 1 shows the importance of the use of protease for eliminating residues of proteins not removed during DNA extraction or added during restriction endonuclease digestions. Samples treated with protease are free of proteins, displaying only kDNA bands.

Figure 2 shows the comparison, in the same gel, of restriction profiles of Trypanosoma cruzi kDNA stained simultaneously with ethidium bromide and with silver. The silver staining is more sensitive, displaying bands which had not been detected by ethidium bromide. 

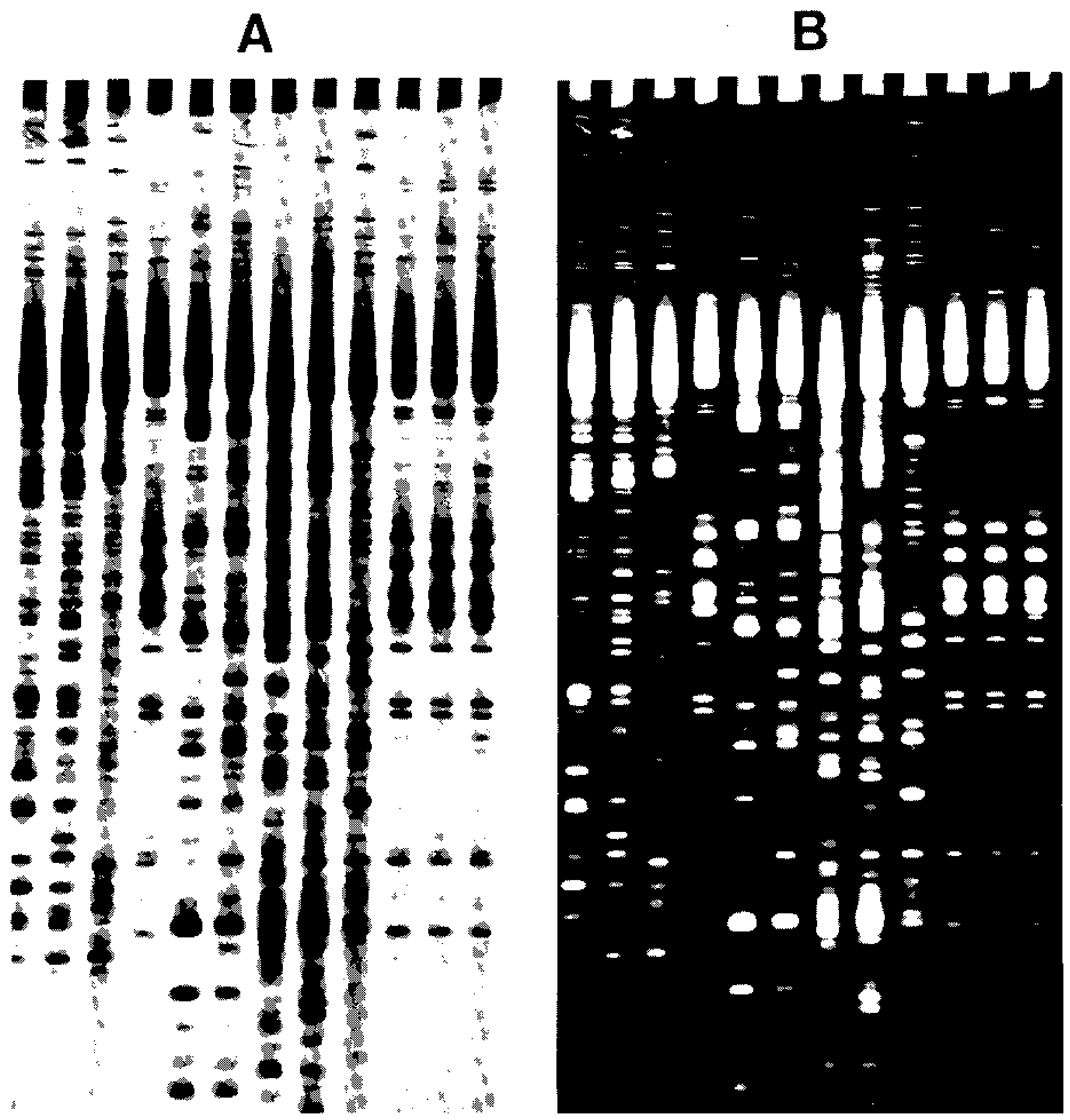

Fig. 3:5-10\% polyacrylamide gradient gel containing kDNA of different strains of Trypanosoma cruzi digested with Hinfl. A) Photo of the gel stained with silver, as described in the text. B) Photo obtained by contact print using the dried gel as negative.

Photographs can be taken using the dried gel as a negative to make contact prints. In Fig. 3 we show this possibility where one can observe the photograph of the gel stained with silver and its respective contact photograph using the dried $\mathrm{gcl}$ as a negative. The picture obtained is similar to a gel stained with ethidium bromide.

Our laboratory is routinely using this methodology for silver staining of DNA, RNA and proteins. As an example, Fig. 4 shows a linear polyacrylamide gradient gel analysis of protein samples which was stained with Coomassie blue and by silver staining.

This methodology, when compared with others for staining polyacrylamide gradient gels, has shown more uniform staining for the whole extension of the gel leaving only a ligh yellowish background. 

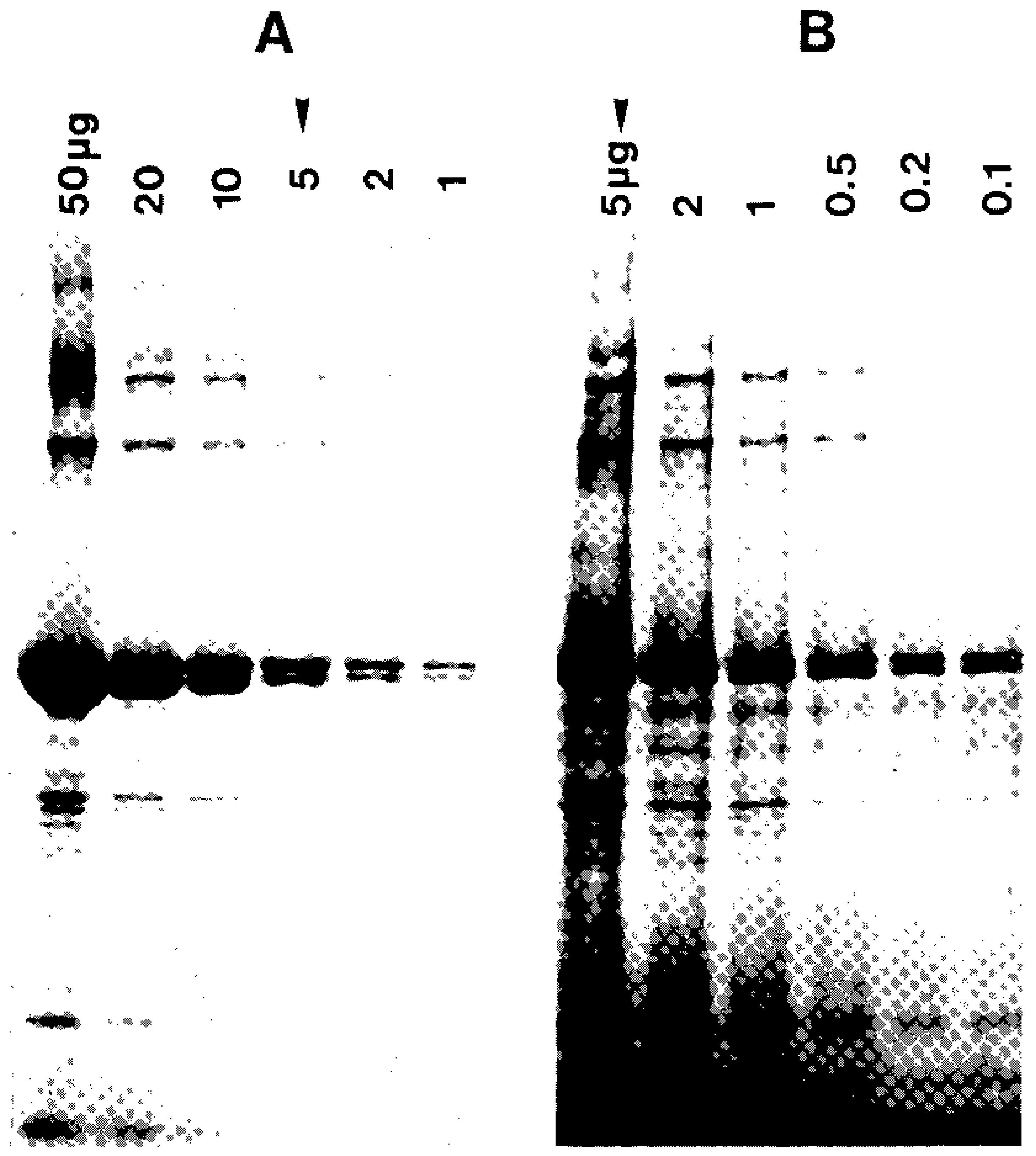

Fig. 4: 5-15\% polyacrylamide gradient gel with SDS, $130 \times 135 \times 1 \mathrm{~mm}$ (W $\times \mathrm{H} \times \mathrm{T}$ ), containing hemolymph of Rhodnius prolixus. A) Stained with Coomassie blue. B) Stained with silver, as described in the text.

\section{ACKNOWLEDGEMENTS}

To Drs H. Momen and Raquel S. Pacheco for the critical reading of this manuscript, and Dr Denise Valle for the photograph made in Fig. 4.

\section{REFERENCES}

BEIDLER, J. L.; HILLIARD, P. R. \& RILL, R. L., 1982. Ultrasensitive staining of nucleic acids with silver. Anal. Biochem., I26: 374-380.

BOULIKAS, T. \& HANCOCK, R., 1981. A highly sensitive technique for staining DNA and RNA in polyacrylamide gels using silver. $J$. Biochem. Biophys. Meth., 5:219-228.

GONÇALVES, A. M.; NEHME, N. S. \& MOREL, C. M., 1984. Trypanosomatid characterization by schizodeme analysis. p. 95-109. In C. M. Morel (Ed.), Genes and Antigens of Parasites. $A$ Labora- tory Manual. 2nd edition. UNDP/World Bank/ WHO Special Programme for Research and Training in Tropical Diseases, Geneva and Fundaçāo Oswaldo Cruz, Rio de Janeiro, Brasil.

GUILLEMETTE, J. G. \& LEWIS, P. N., 1983. Detection of subnanogram quantities of DNA and RNA on native and denaturing polyacrylamide and agarose gels by silver staining. Electrophoresis, 4 : $92-94$.

HERRING, A. J.; INGLIS, N. F.; OJEH, C. K.; SNODGRASS, D. R. \& MENZIS, J. D., 1982. Rapid detection of rotavirus infection by direct detection of viral nucleic acid in silver-stained polyacrylamide gels. J. Clin. Microbiol., 16:473-477.

MERRIL, C. R.; GOLDMAN, D.; SEDMAN, S. A. \& EBERT, M. H., 1981. Ultrasensitive stain for proteins in polyacrylamide gels shows regional variation in cerebrospinal fluid proteins. Science, $211: 1437-1438$.

MOREL, C.; CHIARI, E.; CAMARGO, E. P.;MATTEI, D. M.; ROMANHA, A. J. \& SIMPSON, L., 1980. Strains and clones of Trypanosoma cruzi can be 
characterized by pattern of restriction endonuclease products of kinctoplast DNA minicircles. Proc. Not. Acad. Sci., 77:6810-6814.

OAKLI:Y, B. R.; KIRSCH, D. R. \& MORRIS, N. R., 1980. A simplified ultrasensitive silver stain for detecting proteins in polyacrylamide gels. Anal.
Biochem., 105: 361-363.

SCHLIICHER, M. \& WATTLRSON, D. M., 1983. Analysis of differences between Coomassic blue stain and silver stain procedures in polyacrylamide gels: conditions for the detection of calmodulin and troponin C. Anal. Biochem., 131:312-317. 